\title{
Enhanced Uptake of Iodide from Solutions by Hollow Cu-Based Adsorbents
}

\author{
Ping Mao ${ }^{1, *}$, Jinlong Jiang ${ }^{1,2}, *$, Yichang Pan ${ }^{2}$, Chuansong Duanmu ${ }^{1}$, Shouwen Chen ${ }^{3}$, \\ Yi Yang ${ }^{3}$, Songlan Zhang ${ }^{1}$ and Yonghao Chen ${ }^{1}$ \\ 1 Key Laboratory for Palygorskite Science and Applied Technology of Jiangsu Province, Faculty of Chemical \\ Engineering, Huaiyin Institute of Technology, Huaian 223003, China; cduanmu@hyit.edu.cn (C.D.); \\ zhang3266204738@163.com (S.Z.); cyh1161601314@163.com (Y.C.) \\ 2 State Key Laboratory of Materials-Oriented Chemical Engineering, Nanjing University of Technology, \\ Nanjing 210009, China; panyc@njtech.edu.cn \\ 3 School of Environmental and Biological Engineering, Nanjing University of Science and Technology, \\ Nanjing 210094, China; chensw@njust.edu.cn (S.C.); yangyi@njust.edu.cn (Y.Y.) \\ * Correspondence: pingmao@hyit.edu.cn (P.M.); jiangjinlong75@163.com (J.J.); Tel.: +86-517-8355-9056 (P.M.)
}

Received: 10 April 2018; Accepted: 9 May 2018; Published: 10 May 2018

\begin{abstract}
Cu}_{2} \mathrm{O}$ exhibits excellent adsorption performance for the removal of $\mathrm{I}^{-}$anions from solutions by doping of metallic $\mathrm{Ag}$ or $\mathrm{Cu}$. However, the adsorption process only appears on the surface of adsorbents. To further improve the utilization efficiencies of $\mathrm{Cu}$ content of adsorbents in the uptake process of $\mathrm{I}^{-}$anions, hollow spheres of metallic $\mathrm{Cu}, \mathrm{Cu} / \mathrm{Cu}_{2} \mathrm{O}$ composite and pure $\mathrm{Cu}_{2} \mathrm{O}$ were prepared by a facile solvothermal method. Samples were characterized and employed for the uptake of $\mathrm{I}^{-}$anions under various experimental conditions. The results show that $\mathrm{Cu}$ content can be tuned by adjusting reaction time. After the core was hollowed out, the uptake capacity of the samples increased sharply, and was proportional to the $\mathrm{Cu}$ content. Moreover, the optimal uptake was reached within only few hours. Furthermore, the uptake mechanism is proposed by characterization and analysis of the composites after uptake. Cu-based adsorbents have higher uptake performance when solutions are exposed to air, which further verified the proposed uptake mechanism. Finally, hollow $\mathrm{Cu}$-based adsorbents exhibit excellent selectivity for $\mathrm{I}^{-}$anions in the presence of large concentrations of competitive anions, such as $\mathrm{Cl}^{-}, \mathrm{SO}_{4}{ }^{2-}$ and $\mathrm{NO}_{3}{ }^{-}$, and function well in an acidic or neutral environment. Therefore, this study is expected to promote the development of $\mathrm{Cu}$-based adsorbents into a highly efficient adsorbent for the removal of iodide from solutions.
\end{abstract}

Keywords: Cu-based adsorbent; hollow structure; iodide; uptake; air

\section{Introduction}

In many developing countries, including China, rapid growth in demand has given rise to power shortages. However, the major source of energy is still coal, and constitutes about $75 \%$ of all energy sources, and the reliance on fossil fuels has generated many air pollutants [1,2]. The World Bank (2007) estimated that the total health cost associated with outdoor air pollution in urban areas of China in 2003 was between 157 and 520 billion China Yuan, accounting for 1.2-3.3\% of China's gross domestic product [2]. Therefore, nuclear power, a kind of green energy, has been a priority of the Chinese government [3]. The Energy Development Strategy Action Plan (2014-2020) noted that China's operational nuclear installed capacity could reach 58,000 MWe in 2020, with 30,000 MWe more under construction [4]. Unfortunately, as inevitable products of nuclear fission, radioactive iodine species can easily dissolve into solutions. The half-life of radioactive iodine differs from about 8 days $\left({ }^{131} \mathrm{I}\right)$ to $1.6 \times 10^{7}$ years $\left({ }^{129} \mathrm{I}\right)$. Radioactive iodine poses a potential toxicity due to its ability to diffuse in solution 
as an anion and bioaccumulation through the food chain and subsequent dysfunction of the thyroid gland. Therefore, effective uptake of radioactive iodide from solutions will play an irreplaceably vital role in the safety use of nuclear power.

Many means have been used for the treatment of radioactive iodide from contaminated water, such as physical adsorption [5], ion exchange [6], membrane separation [7,8] and chemical precipitation [9], etc. Notably, chemical precipitation is an efficient and easy method that is suitable for safe storage and the emergency treatment of radionuclide in a nuclear dump or polluted water source. Various metal-based adsorbents were reported over the last decades [10-12]. Due to their good environmental tolerance, inexpensiveness and relatively low toxicity, $\mathrm{Cu}^{+}$-based adsorbents are expected to be the best candidates. Whereas, $\mathrm{Cu}^{2+}$ species, oxidized from surface $\mathrm{Cu}^{+}$by dissolved oxygen, appear on the surface of the cuprous adsorbents that hinder the reaction of $\mathrm{Cu}^{+}$ and $\mathrm{I}^{-}$anions [13]. Therefore, to address this problem, we doped metallic $\mathrm{Ag}$ - or $\mathrm{Cu}$ - into $\mathrm{Cu}_{2} \mathrm{O}$ adsorbents [14-16]. The adsorption mechanism involves $\mathrm{Cu}_{2} \mathrm{O}\left(\mathrm{Ag}_{2} \mathrm{O}\right)$ formed by the reaction of metallic $\mathrm{Cu}(\mathrm{Ag})$ and the surface-oxidized $\mathrm{CuO}$ adsorbs $\mathrm{I}^{-}$anions. However, the utilization efficiencies of $\mathrm{Cu}$ content in these adsorbents are small because of the aforementioned surface adsorption mechanism. Therefore, we want to improve the utilization efficiency of adsorbence through the design of the hollow structure of $\mathrm{Cu}$-based adsorbents.

To the best of our knowledge, the application of various templates, including hard templates, soft templates and self-sacrificial templates, are the main synthetic strategies for the preparation of hollow $\mathrm{Cu}$-based nanomaterials [17-21]. However, it remains a challenge to achieve the facile synthesis of $\mathrm{Cu} / \mathrm{Cu}_{2} \mathrm{O}$ composite spheres with a hollow interior.

Herein, we prepared hollow spheres of metallic $\mathrm{Cu}, \mathrm{Cu} / \mathrm{Cu}_{2} \mathrm{O}$ composite and pure $\mathrm{Cu}_{2} \mathrm{O}$ via a facile solvothermal method. A controllable composition of $\mathrm{Cu}$ and $\mathrm{Cu}_{2} \mathrm{O}$ can easily be obtained by adjusting the reaction time. Meanwhile, the hollow $\mathrm{Cu}$-based samples were used to improve its uptake capacity for $\mathrm{I}^{-}$anions from water exposed to air. Furthermore, uptake performances of the hollow $\mathrm{Cu}, \mathrm{Cu} / \mathrm{Cu}_{2} \mathrm{O}$ and $\mathrm{Cu}_{2} \mathrm{O}$ were studied. Factors affecting the uptake of iodide by the hollow $\mathrm{Cu}$-based samples were also conducted.

\section{Experimental Section}

\subsection{Synthesis of Hollow Cu-Based Adsorbents}

All chemicals from commercial sources were of reagent grade and used without further purification. The experiment was derived from one reported in the literature [18]. The synthesis procedure is as follows: $0.4 \mathrm{mmol} \mathrm{CuSO} \cdot 5 \mathrm{H}_{2} \mathrm{O}$ and $20 \mathrm{mmol}$ cetyltrimethylammonium bromide $(\mathrm{CTAB})$ used as soft template for the transcriptive synthesis of hollow nanostructures were dissolved in $200 \mathrm{~mL}$ deionized water, followed by vigorous stirring and heating to $80^{\circ} \mathrm{C}$. The color of this mixture was pale blue $\left(\mathrm{Cu}^{2+}\right)$ (Figure 1a). The introduction of $2 \mathrm{mmol}$ of ascorbic acid acted as reducing agent and led to the formation of a colorless transparent solution $\left(\mathrm{Cu}^{+}\right)$(Figure $\left.1 \mathrm{~b}\right)$. The solution was then stirred at $80^{\circ} \mathrm{C}$ for $20 \mathrm{~min}$. A yellow precipitate $(\mathrm{CuOH})$ (Figure 1c) was produced when $4 \mathrm{~mL}$ of $\mathrm{NaOH}$ solution ( $0.1 \mathrm{M}$ in water) was added dropwise to the above solution. As shown in Figure 1, the color of the solution turned from yellow to brown when the reaction time further increased. After stirring for a certain time, the precipitate was centrifuged, washed sequentially with deionized water and ethanol several times, and then dried at $40{ }^{\circ} \mathrm{C}$ for $10 \mathrm{~h}$ under vacuum. The as-synthesized samples were designated as $\mathrm{SX}$, and the samples after the uptake of $\mathrm{I}^{-}$anions were designated as I-SX, where $X$ denotes the reaction time ( $\mathrm{min})$. 


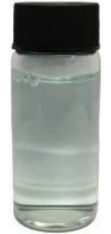

(a)

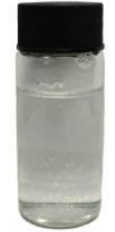

(b)

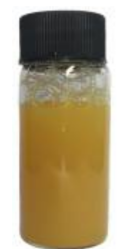

(c)

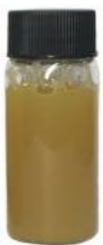

(d)

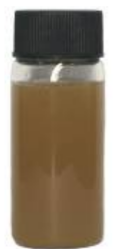

(e)

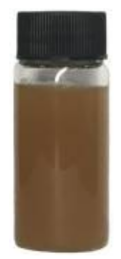

(f)

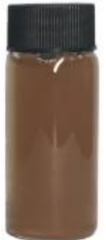

$(\mathrm{g})$

Figure 1. Photographs showing the solution color changes during the course of the as-synthesized samples' formation process. (a) After mixing $\mathrm{CuSO}_{4} \cdot 5 \mathrm{H}_{2} \mathrm{O}$ and cetyltrimethylammonium bromide (CTAB); (b) immediately after ascorbic acid was added; (c) 0 min; (d) 5 min; (e) $20 \mathrm{~min}$; (f) $40 \mathrm{~min}$ and (g) 60 min after adding $\mathrm{NaOH}$.

\subsection{Characterization}

The phase purity and crystal structure of the as-synthesized samples were obtained by X-ray diffraction (XRD) on a D8 Advance X-ray diffractometer (Bruker AXS Company, Karlsruhe, Germany) with $\mathrm{Cu} \mathrm{K} \alpha$ radiation $(\mathrm{A}=1.5406 \AA)$ at $40 \mathrm{KV}$ and $40 \mathrm{~mA}$. The morphologies and microstructures of the samples were examined on an FEI Quanta 250FEG scanning electron microscope (SEM) and an FEI Tecnai G20 transmission electron microscope (TEM) (FEI, Hillsboro, OR, USA). The Brunauer-Emmett-Teller (BET) specific surface area of the samples was measured by using nitrogen adsorption and desorption at a constant temperature of $-195{ }^{\circ} \mathrm{C}$ on a Micromeritics Tristar 3020 specific surface and porosity analyzer (Micromeritics Instrument Corporation, Norcross, GA, USA). Furthermore, X-ray photoelectron spectroscopy (XPS) spectra of the samples were obtained on a PHI Quantera II electron spectrometer (Physical Electronics GmbH, Ismaning, Germany) using monochromated $\mathrm{Al} \mathrm{Ka}$ radiation as the excitation source.

\subsection{Batch Experiments}

In this work, all $\mathrm{I}^{-}$anions' uptake experiments were carried out with non-radioactive ${ }^{127} \mathrm{I}^{-}$ (NaI) in aqueous solution because of the high radiation dose and toxicity of radioactive iodide (e.g., $\left.{ }^{131} \mathrm{I},{ }^{125} \mathrm{I},{ }^{129} \mathrm{I}\right)$. Since the concentration of iodide released by nuclear fuel waste is predicted to be below $3 \times 10^{-4} \mathrm{M}$ [22], all uptake experiments were carried out with an initial iodide concentration of $10^{-4} \mathrm{M}$. The as-synthesized samples $(50 \mathrm{mg}$ ) were added to $50 \mathrm{~mL}$ of iodide (NaI) solution in $100 \mathrm{~mL}$ Erlenmeyer flasks. The flasks were constantly shaken for $6 \mathrm{~h}$ in a shaking incubator at $150 \mathrm{rpm}$. Unless otherwise mentioned, all experiments with solutions exposed to air were tested. Afterward, the solids and solutions were separated by centrifugation, and the supernatants were analyzed by an ultraviolet spectrophotometer (UV-vis) at $227 \mathrm{~nm}$ to determine the remaining $\mathrm{I}^{-}$anions in the solutions. The effects of the uptake parameters (initial iodide concentration, solution $\mathrm{pH}$, uptake time, etc.) were investigated. The initial iodide concentrations ranged from 0.04 to $0.40 \mathrm{mM}$. Kinetic studies were conducted using an iodide concentration of $0.40 \mathrm{mM}$ for different time intervals. The $\mathrm{pH}$ of the solution was adjusted to values between 3 and 10 using $0.1 \mathrm{M} \mathrm{HCl}$ or $0.1 \mathrm{M} \mathrm{NaOH}$. The selective uptake studies were determined using iodide concentration of $0.40 \mathrm{mM}$ in the presence of high concentrations of $\mathrm{Cl}^{-}, \mathrm{NO}_{3}{ }^{-}, \mathrm{SO}_{4}{ }^{2-}$, and $\mathrm{CO}_{3}{ }^{2-}$ anions. The iodide concentration was measured by iodine blue spectrophotometry. The uptake performances of the hollow $\mathrm{Cu}$-based adsorbents in an $\mathrm{Ar}_{2} \mathrm{or}_{2}$ environment were further studied. Every experiment was analyzed in triplicate, and the average values were utilized to calculate the uptake capacities. The uptake capacity $\left(q_{e}\right)$, uptake efficiency $(\eta)$ and uptake rate $(r)$ were calculated using the following mathematical equations, respectively:

$$
\begin{gathered}
q_{e}=\left(C_{0}-C_{e}\right) \frac{V}{m} \\
\eta=\frac{C_{0}-C_{e}}{C_{0}} \times 100 \%
\end{gathered}
$$




$$
r=\frac{q_{e}}{t_{e}}
$$

where $q_{e}$ is the amount of iodide uptake on the as-synthesized samples at equilibrium time $\left(\mathrm{mmol} \mathrm{g}^{-1}\right)$, $C_{0}$ and $C_{e}$ are the initial and equilibrium iodide concentration $(\mathrm{mM})$ in the solution, respectively, $V$ is the volume (L) of iodide solution, and $m$ is the mass of the as-synthesized samples ( $g$ ), $t_{e}$ is equilibration time.

\section{Results and Discussion}

\subsection{Characterization}

XRD measurements were used to gain insights into the chemical composition of the as-synthesized samples, as shown in Figure 2a. It can be observed that S5 exhibited many diffraction peaks at $29.6^{\circ}$, $36.5^{\circ}, 42.4^{\circ}, 61.5^{\circ}$ and $73.7^{\circ}$, corresponding to the diffractions from the (110), (111), (200), (220) and (311) crystalline planes of $\mathrm{Cu}_{2} \mathrm{O}$ (JCPDS 65-3288) [23]. By increasing the reaction time, the characteristic peaks of $\mathrm{Cu}_{2} \mathrm{O}$ become weaker; however, the peaks at $43.3^{\circ}, 50.4^{\circ}$ and $74.1^{\circ}$, indexed to the (111), (200) and (220) crystalline planes of metallic Cu (JCPDS 65-9026) [24], become stronger, revealing the generation of an increasingly metallic $\mathrm{Cu}$ with the reaction time increased. Moreover, the metallic $\mathrm{Cu}$ content of four samples, calculated according to the peak areas of XRD patterns, is about $0,24.2 \%$, $60.6 \%$, and $100 \%$, respectively. Meanwhile, inset in Figure 2 shows the photos of the as-synthesized samples. The color gradually turns from yellow into green and then brown, with the changes resulting from the growth of the content of metallic $\mathrm{Cu}$. Moreover, the surface properties of S40 were also examined by XPS measurement. As shown in Figure $2 b$, the binding energies are calibrated by $C$ $1 \mathrm{~s}(284.8 \mathrm{eV}), \mathrm{Cu} 2 \mathrm{p}$ peaks were investigated in detail to obtain the chemical state and structural characteristics. The main peaks at $932 \mathrm{eV}$ and $952 \mathrm{eV}$ of the $\mathrm{Cu} 2 \mathrm{p}$ XPS spectrum (inset in Figure 2b) can be fitted to two peaks, respectively. The peaks at $932.2 \mathrm{eV}$ and $952.2 \mathrm{eV}$ are attributed to the binding energies of $\mathrm{Cu} 2 \mathrm{p}_{3 / 2}$ and $\mathrm{Cu} 2 \mathrm{p}_{1 / 2}$ of $\mathrm{Cu}_{2} \mathrm{O}$, respectively [25]. The peaks at $934.5 \mathrm{eV}$ and $954.4 \mathrm{eV}$ and two small satellite peaks at $942 \mathrm{eV}$ and $962 \mathrm{eV}$, corresponding to the binding energies of $\mathrm{CuO}$ [26], confirm the presence of $\mathrm{CuO}$ on the surface of $\mathrm{S} 40$. No $\mathrm{CuO}$ phase can be observed from XRD patterns since XPS is much more sensitive compared to XRD.
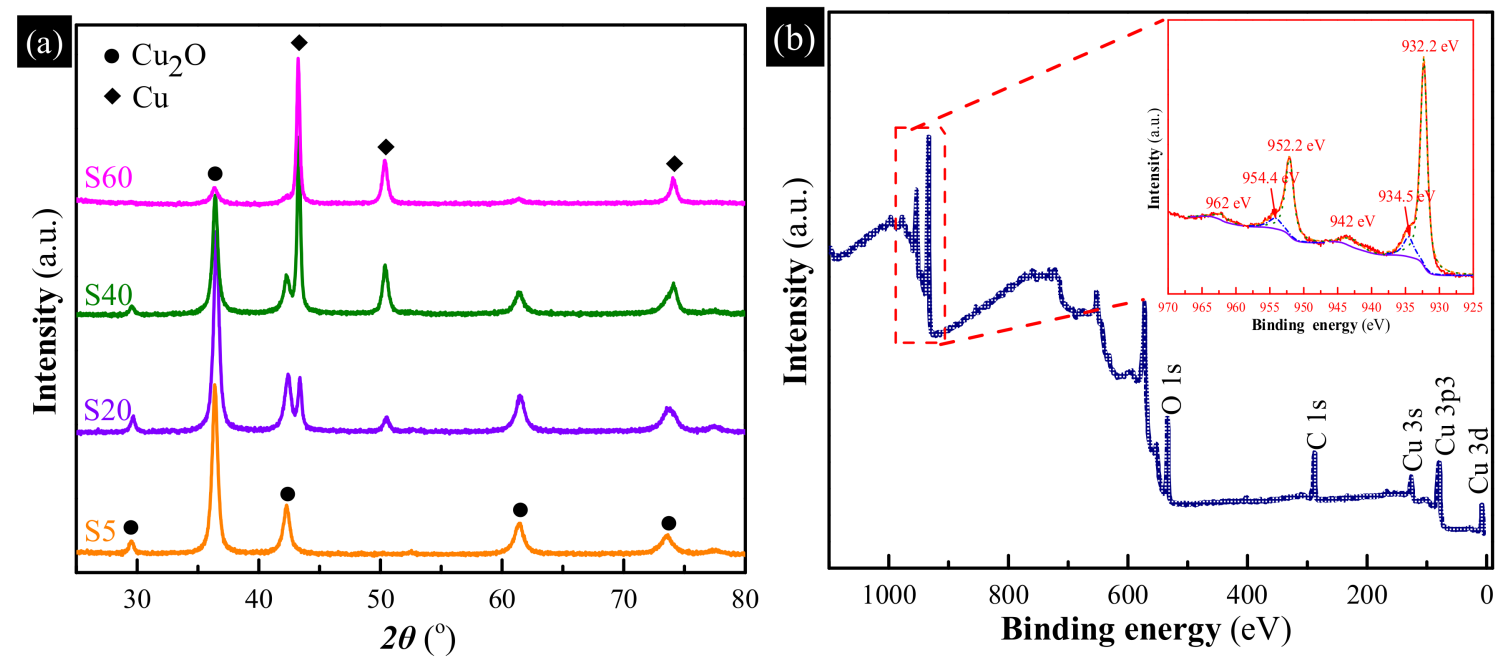

Figure 2. (a) X-ray diffraction (XRD) patterns of the as-synthesized samples obtained with different reaction time, inset are photos of the as-synthesized samples; (b) X-ray photoelectron spectroscopy (XPS) patterns of S40, inset is the high-resolution spectrum of the $\mathrm{Cu} 2 \mathrm{p}$ peaks.

Figure 3 displays SEM and TEM images of the as-synthesized samples. As revealed in the SEM images, all as-synthesized samples possessed a spherical and subglobular shape with an average 
size of $200 \mathrm{~nm}$ that consisted of many nanoparticles. Lots of pores existed on the surface of the samples. However, the number of the pores decreased with increasing reaction time. The BET results further confirmed this point. The BET surface areas of S5, S20, S40 and S60, as measured by the nitrogen adsorption-desorption method, was about 5.13, 5.01, 3.53 and $1.71 \mathrm{~m}^{2} \mathrm{~g}^{-1}$, respectively. Meanwhile, TEM images (inset in Figure 3) showed that the interior space of the samples is empty, and all as-synthesized samples are hollow spheres. TEM images further verified that the samples consisted of many nanoparticles, which are consistent with the SEM results. The shells of these hollow spheres are single-crystalline; this property makes these structures more stable [18].
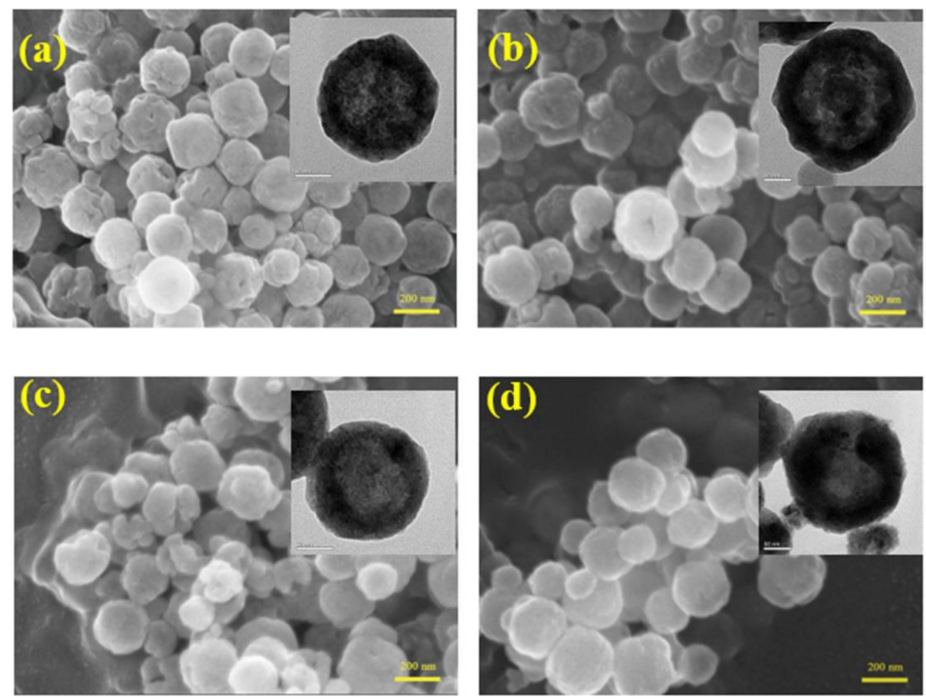

Figure 3. Scanning electron microscope (SEM) and transmission electron microscope (TEM) (inset) photos of S5 (a); S20 (b); S40 (c) and S60 (d).

\subsection{Uptake Performance Studies}

\subsubsection{Uptake Equilibrium Isotherms}

To understand the uptake performance of the hollow $\mathrm{Cu}$-based adsorbents, the $\mathrm{I}^{-}$anions equilibrium uptake isotherms of all synthesized samples with different initial iodide concentrations were obtained. The results are shown in Figure 4a. It is evident that the uptake capacities of all samples progressively increase with increasing concentration of $\mathrm{I}^{-}$anions, and finally reach the saturation states. The uptake efficiencies of $\mathrm{S} 40$ and $\mathrm{S} 60 \mathrm{for} \mathrm{I}^{-}$anions are higher than $99 \%$ when the concentration of $\mathrm{I}^{-}$anions in under $0.16 \mathrm{M}$. Moreover, the maximum uptake capacity of all samples increases as the content of metallic $\mathrm{Cu}$ increased, which is similar to the previous report [15]. It is also apparent that the quantity of $\mathrm{I}^{-}$anions adsorbed per unit mass is $0.03 \mathrm{mmol} \mathrm{g}^{-1}$ for S5, $0.20 \mathrm{mmol} \mathrm{g}^{-1}$ for S20, $0.25 \mathrm{mmol} \mathrm{g}^{-1}$ for S40 and $0.26 \mathrm{mmol} \mathrm{g}^{-1}$ for S60, respectively. Furthermore, as summarized in Table 1, by comparing the uptake capacity of all hollow $\mathrm{Cu}$-based adsorbents with the previous reported $\mathrm{Cu}$-based adsorbents, it could be found that the uptake capacity of pure $\mathrm{Cu}_{2} \mathrm{O}$ increased from 0.02 to $0.03 \mathrm{mmol} \mathrm{g}^{-1}$. Meanwhile, the content of metallic $\mathrm{Cu}$ declined by $7.6 \%$, however, the uptake capacity increased from $0.18 \mathrm{mmol} \mathrm{g}^{-1}$ for $\mathrm{Cu} / \mathrm{Cu}_{2} \mathrm{O}$ hybrid to $0.03 \mathrm{mmol} \mathrm{g}^{-1}$ for S20. This implies that the samples with hollow structure have higher utilization efficiency of $\mathrm{Cu}$. 

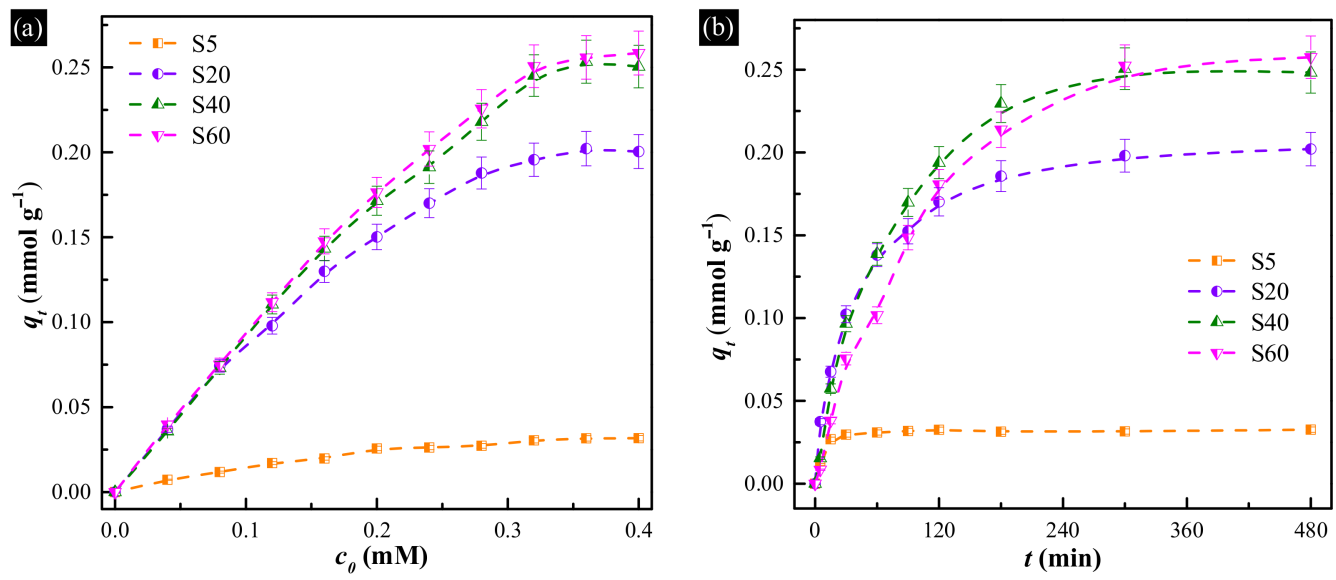

Figure 4. (a) Uptake isotherms of all hollow Cu-based adsorbents for $\mathrm{I}^{-}$anions over $12 \mathrm{~h}$; (b) uptake kinetics of all hollow $\mathrm{Cu}$-based adsorbents in $0.4 \mathrm{mM} \mathrm{I}^{-}$anions.

Table 1. Comparison of the iodide uptake capacities of several previously reported $\mathrm{Cu}$ based adsorbents.

\begin{tabular}{ccccc}
\hline Sample & pH Value & Temperature $\left({ }^{\circ} \mathbf{C}\right)$ & Removal Capacity $\left(\mathbf{m m o l ~ g}^{\mathbf{- 1}}\right)$ & Ref. \\
\hline $\mathrm{S} 5\left(\mathrm{Cu}_{2} \mathrm{O}\right)$ & 7 & 25 & 0.03 & This work \\
$\mathrm{S} 20\left(24.2 \%-\mathrm{Cu} / \mathrm{Cu}_{2} \mathrm{O}\right)$ & 7 & 25 & 0.20 & This work \\
$\mathrm{S} 40\left(60.6 \%-\mathrm{Cu} / \mathrm{Cu}_{2} \mathrm{O}\right)$ & 7 & 25 & 0.25 & This work \\
$\mathrm{S} 60(\mathrm{Cu})$ & 7 & 25 & 0.26 & This work \\
$\mathrm{Cu}_{2} \mathrm{O}^{a}$ & 6.7 & 25 & 0.002 & Ref. [13] \\
$31.8 \%-\mathrm{Cu}^{a} \mathrm{Cu}_{2} \mathrm{O}$ & 7 & 25 & 0.18 & Ref. [14,15] \\
$\mathrm{Cu} \mathrm{C}_{2} \mathrm{O}$ & 7 & 25 & 0.02 & Ref. [14,15] \\
$1.0 \%-\mathrm{Ag}_{\mathrm{C} C \mathrm{Cu}_{2} \mathrm{O}}$ & 7 & 25 & 0.20 & Ref. [14] \\
$\mathrm{Cu}$ & 7 & 22 & 0.05 & Ref. [27] \\
$\mathrm{CuO}$ & 7 & 22 & 0.002 & Ref. [27] \\
$\mathrm{Cu}$ & 7 & 22 & 0.016 & Ref. [27] \\
$\mathrm{Cu}_{2} \mathrm{~S}^{a}$ & 7 & 25 & 0.048 & Ref. [28] \\
$\mathrm{CuCl}^{b}$ & 7 & 25 & 2.0 & Ref. [29] \\
\hline
\end{tabular}

${ }^{a}$ Experiments were carried out in $0.1 \mathrm{M} \mathrm{NaClO}_{4} ;{ }^{b}$ Experiments were carried out in $130 \mathrm{mg} \mathrm{L}{ }^{-1} \mathrm{Na}_{2} \mathrm{SO}_{3}$.

\subsubsection{Uptake Kinetics}

The Langmuir and Freundlich isotherm models were used for supplementary investigations into the uptake process. The mathematical representations of them are described as Equations (4) and (5), respectively:

$$
\begin{gathered}
\frac{C_{e}}{q_{e}}=\frac{1}{q_{m} b}+\frac{C_{e}}{q_{m}} \\
\ln q_{e}=\frac{1}{n} \ln C_{e}+\ln K_{f}
\end{gathered}
$$

where $q_{m}\left(\mathrm{mmol} \mathrm{g}^{-1}\right)$ is the theoretical maximum uptake capacity, $b$ and $K_{f}$ are the uptake constants of the Langmuir and Freundlich models, respectively, and $n$ is the Freundlich linearity index.

The Langmuir adsorption model assumes that adsorption occurs on a homogeneous surface by monolayer adsorption without any interactions between the adsorbed anions [30,31]. As depicted in Figure S1a and Table S1, the good straight line shows that the uptake process followed the Langmuir isotherm. The monolayer uptake capacity was estimated to be $0.05,0.22,0.29$ and $0.27 \mathrm{mmol}$ $\mathrm{g}^{-1}$ for S5, S20, S40 and S60, respectively, which is similar to the above uptake isotherm results. By contrast, the Freundlich isotherm is an empirical model and can be used to describe adsorption on heterogeneous surfaces as well as multilayer adsorption [32]. As shown in Figure S1b and Table S1, the linear regressions of all samples did not fit well, compared with those from the Langmuir model. This further confirms that the Langmuir adsorption model is a good model of the adsorption system, 
which suggests the homogeneous nature of uptake sites on the surface of the hollow $\mathrm{Cu}$-based samples with a monolayer adsorption.

To determine the uptake rates of the hollow Cu-based adsorbents, the kinetic of the uptake of $\mathrm{I}^{-}$anions was plotted at initial iodide concentration of $0.40 \mathrm{mM}$, as shown in Figure $4 \mathrm{~b}$. The result revealed that the uptake reached optimal removal within 60, 300, 300 and 480 min for S5, S20, S40 and S60, respectively. After reaching the saturation value, a continuous and smooth graph was obtained. Therefore, the uptake rates $(r)$ of all samples were $0.03,0.04,0.05$ and $0.03 \mathrm{mmol} \mathrm{g}^{-1} \mathrm{~h}^{-1}$, which indicates that $\mathrm{S} 40$ is the best candidate for the removal of $\mathrm{I}^{-}$anions.

The pseudo-first-order and pseudo-second-order models [33] were used to perform data fitting. The mathematical representations are given below:

$$
\begin{gathered}
\ln \left(q_{m}-q_{t}\right)=\ln q_{m}-k_{1} t \\
\frac{t}{q_{t}}=\frac{1}{k_{2} q_{m}^{2}}+\frac{1}{q_{m}} t
\end{gathered}
$$

where $q_{t}\left(\mathrm{mmol} \mathrm{g}^{-1}\right)$ represents the uptake capacity at time $t(\mathrm{~min}), k_{1}$ and $k_{2}\left(\mathrm{~g} \mathrm{mmol}^{-1} \mathrm{~min}^{-1}\right)$ are the pseudo-first-order rate constant and the pseudo-second-order rate constant. As depicted in Figure S2, the graphs of $t / q_{t}$ versus $t$ and $\ln \left(q_{e}-q_{t}\right)$ versus $t$ were plotted. The pseudo-first-order rate constants and pseudo-second-order rate constants are summarized in Table S2. According to the linear regression coefficients $\left(R^{2}\right)$ of the kinetic models, the second-order kinetic of every sample fits better than its first-order kinetic during the uptake process. The pseudo-second-order kinetic model is used to predict the kinetic behavior of adsorption with chemical adsorption being the rate-controlling step [33]. Therefore, chemical adsorption dominated the uptake process of the hollow $\mathrm{Cu}$-based adsorbents.

\subsection{Uptake Mechanism}

To analyze the uptake mechanism of the hollow Cu-based adsorbents, XRD and XPS measurement of the samples after the uptake of $\mathrm{I}^{-}$anions were conducted. As shown in Figure 5a, the diffraction peaks assigned to metallic $\mathrm{Cu}$ become weaken, but a new peak ascribed to CuI (JCPDS 06-0246) [34] at $25.5^{\circ}$ can be found. Meanwhile, Figure S3 shows that the solution colors of all hollow Cu-based adsorbents change to yellow or dark yellow. This further implied that the content of metallic $\mathrm{Cu}$ decreased. All of this implied that the $\mathrm{CuI}$ and metallic $\mathrm{Cu}$ were the uptake product and reactant in the uptake process, respectively. Moreover, XPS patterns of I-S40 (Figure 5b) revealed that the peaks ascribed to $\mathrm{Cu}^{2+}$ disappeared, indicating that $\mathrm{Cu}^{2+}$ is also the reactant. Furthermore, the I $3 \mathrm{~d}$ core level appeared at the binding energies of around $630.7 \mathrm{eV}$ and $619.3 \mathrm{eV}$ assigned to $\mathrm{CuI}$ [35], further confirming that $\mathrm{CuI}$ was the uptake product. Therefore, the probable uptake mechanism for hollow $\mathrm{Cu}$-based adsorbents can be proposed. Pure $\mathrm{Cu}_{2} \mathrm{O}$ hardly reacts with $\mathrm{I}^{-}$anions because of the $\mathrm{CuO}$ surface layer. For the uptake mechanism of $\mathrm{Cu} / \mathrm{Cu}_{2} \mathrm{O}$ and pure metallic $\mathrm{Cu}$, part metallic $\mathrm{Cu}$ and $\mathrm{Cu}_{2} \mathrm{O}$ can be oxidized to $\mathrm{CuO}$ by dissolved oxygen. Then, metallic $\mathrm{Cu}$ reacts with $\mathrm{CuO}$ to generate $\mathrm{Cu}_{2} \mathrm{O}$. Subsequently, generated $\mathrm{Cu}_{2} \mathrm{O}$ reacts with $\mathrm{I}^{-}$anions to form $\mathrm{CuI}$. In brief, the uptake processes can be summarized as follows:

$$
\begin{gathered}
\mathrm{Cu}+\mathrm{CuO} \leftrightarrow \mathrm{Cu}_{2} \mathrm{O} \\
\mathrm{Cu}_{2} \mathrm{O}+2 \mathrm{I}^{-}+\mathrm{H}_{2} \mathrm{O} \rightarrow 2 \mathrm{CuI}+2 \mathrm{OH}^{-}
\end{gathered}
$$

To further verify the importance of the dissolved oxygen during the uptake process of the $\mathrm{Cu}$-based adsorbents, the uptake experiments were performed in $\mathrm{Ar}_{2}, \mathrm{O}_{2}$ and sealed air atmosphere, respectively. The results are presented in Figure 6a. The uptake efficiency of every Cu-based adsorbent decreased sharply in the air atmosphere. Even when the flask was sealed, the uptake efficiencies of all hollow Cu-based adsorbents decreased to about 1.0\%, 29.8\%, 30.4\% and 31.3\%, respectively. This further verified that oxygen is of importance in the uptake. However, the uptake efficiencies of the samples also decreased sharply in the $\mathrm{O}_{2}$ atmosphere. This indicates that excess oxygen is detrimental 
to the uptake. The probable reason is that metallic and $\mathrm{Cu}_{2} \mathrm{O}$ can be oxidized to $\mathrm{CuO}$ by excess oxygen, or the uptake reactions have been severely disrupted by the floating gas.
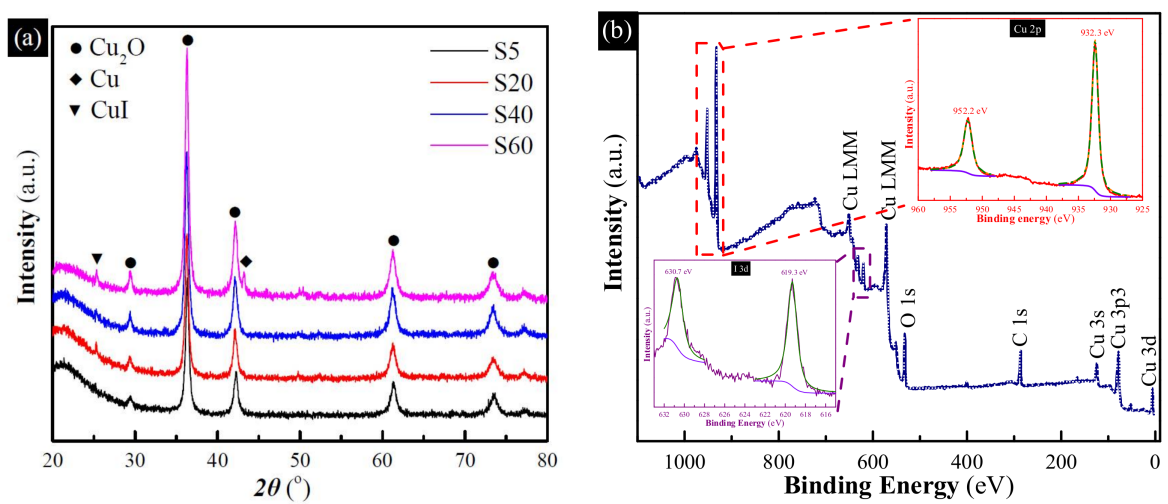

Figure 5. (a) XRD patterns of hollow $\mathrm{Cu}$-based adsorbents after the uptake of $\mathrm{I}^{-}$anions; (b) XPS patterns of $\mathrm{S} 40$ after the uptake of $\mathrm{I}^{-}$anions, inset are the high-resolution spectra of $\mathrm{Cu} 2 \mathrm{p}$ and I $3 \mathrm{~d}$ peaks, respectively.
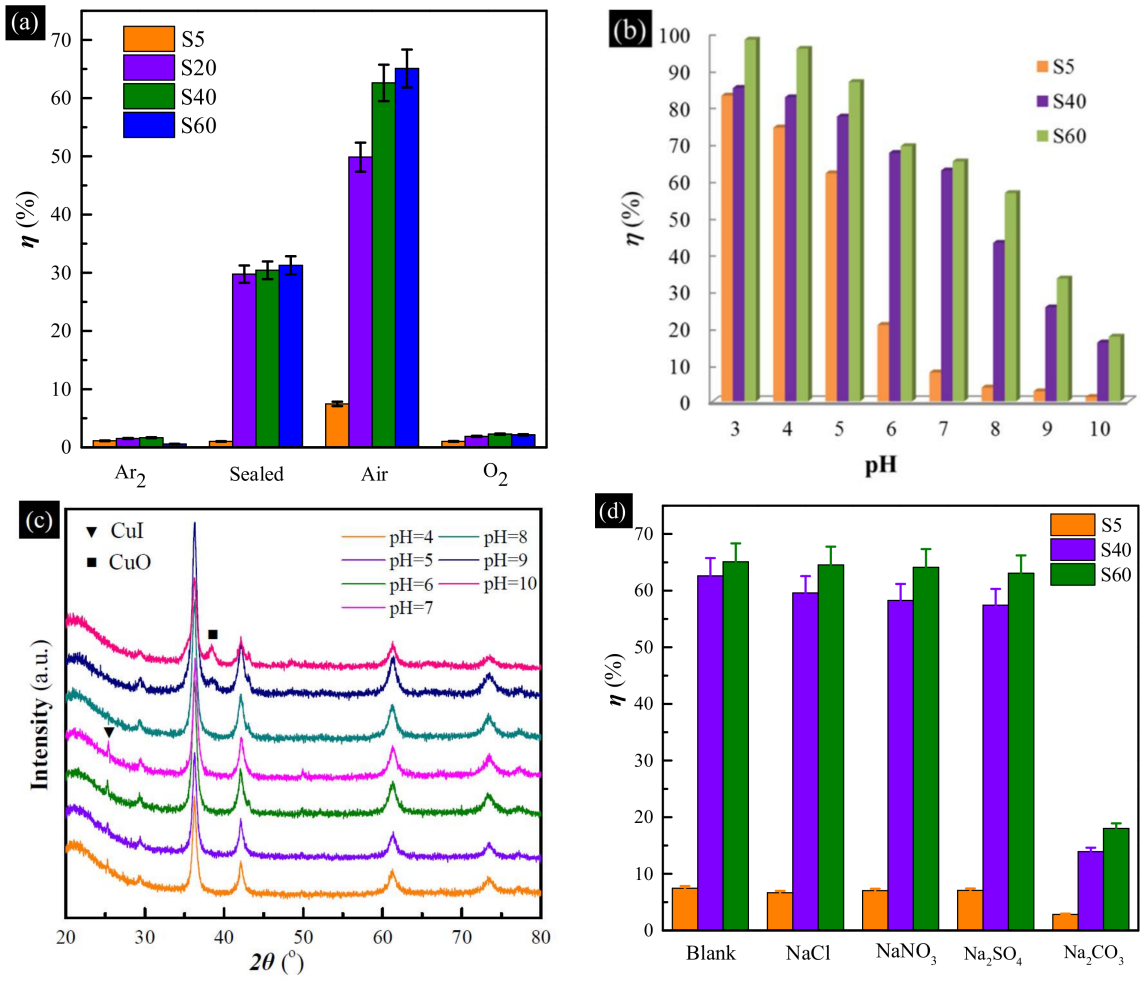

Figure 6. (a) Effect of different atmospheres on the uptake of $\mathrm{I}^{-}$anions by hollow Cu-based adsorbents; (b) uptake efficiency of $\mathrm{I}^{-}$anions in the $\mathrm{pH}$ range from 3 to 10; (c) XRD patterns of S40 after the uptake of $\mathrm{I}^{-}$anions at different $\mathrm{pH}$ values; (d) effect of high competitive anions on the uptake of $\mathrm{I}^{-}$anions by hollow Cu-based adsorbents.

\subsection{Effect of Factors}

\subsubsection{Effect of $\mathrm{pH}$}

To investigate the effect of $\mathrm{pH}$ on the uptake of $\mathrm{I}^{-}$anions by hollow $\mathrm{Cu}$-based adsorbents, $\mathrm{pH}$ values ranging from 3 to 10 and the samples of S5, S40 and S60 were chosen. As shown in Figure 6b, with the increase in $\mathrm{pH}$ of the solution, the uptake efficiency is found to decrease in the case of all 
samples, implying that acidic medium is helpful for the uptake of $\mathrm{I}^{-}$anions by the hollow Cu-based adsorbents, but the alkaline environment has an adverse effect. XRD patterns (Figure 6c) of S40 after the uptake of $\mathrm{I}^{-}$anions at different $\mathrm{pH}$ values can be used to explain the above phenomenon. When $\mathrm{pH}$ value decreased from 7 to 3 , a diffraction peak at $25.5^{\circ}$, corresponding to the diffraction from the (111) crystalline plane of CuI (JCPDS 06-0246) [34], can be found in the pH range of 3-7. $\mathrm{CuO}, \mathrm{Cu}_{2} \mathrm{O}$ and $\mathrm{Cu}$ can partially be dissolved in an acidic solution, forming $\mathrm{Cu}^{2+}$ and $\mathrm{Cu}^{+}$species, which are helpful for generating CuI precipitate [29]. However, another diffraction peak at $38.7^{\circ}$, assigned to the (111) crystalline plane of $\mathrm{CuO}$ (JCPDS 48-1548) [36] became stronger when $\mathrm{pH}$ value increased to 9 . In an alkaline environment, $\mathrm{Cu}$ and $\mathrm{Cu}_{2} \mathrm{O}$ can easily be oxidized to $\mathrm{CuO}$ that cannot reaction with $\mathrm{I}^{-}$anions [15].

\subsubsection{Selective Uptake}

To understand the selective uptake of $\mathrm{I}^{-}$anions by the hollow $\mathrm{Cu}$-based adsorbents, a series of experiments in the presence of high concentrations of $\mathrm{Cl}^{-}, \mathrm{NO}_{3}{ }^{-}, \mathrm{SO}_{4}{ }^{2-}$ and $\mathrm{CO}_{3}{ }^{2-}$ anions $(40 \mathrm{mM})$ were conducted. The uptake results are shown in Figure $6 \mathrm{~d}$. No obvious difference can be found in the presence of high concentrations of $\mathrm{Cl}^{-}, \mathrm{NO}_{3}{ }^{-}$and $\mathrm{SO}_{4}{ }^{2-}$ anions. However, uptake performance of all samples drops off rapidly in the presence of high concentrations of $\mathrm{CO}_{3}{ }^{2-}$ anions. It is evident from Figure $\mathrm{S} 4$ that many diffraction peaks assigned to $\mathrm{CuI}$ can be found in the presence of $\mathrm{Cl}^{-}, \mathrm{NO}_{3}{ }^{-}$and $\mathrm{SO}_{4}{ }^{2-}$ anions, and the results were in accordance with those obtained without the competitive anions. However, many peaks, corresponding to $\mathrm{CuO}$, can be found in the presence of $\mathrm{CO}_{3}{ }^{2-}$ anions. $\mathrm{Cu}$ and $\mathrm{Cu}_{2} \mathrm{O}$ can also be oxidized to $\mathrm{CuO}$ in a weakly alkaline environment. As we know, both $\mathrm{CuI}$ and $\mathrm{CuCl}$ are precipitates. However, the solubility products $\left(K_{s p}{ }^{\Phi}\right)$ of $\mathrm{CuCl}$ and $\mathrm{CuI}$ are $1.2 \times 10^{-6}$ and $1.1 \times 10^{-12}$, respectively. When the concentration of $\mathrm{Cl}^{-}$is about $40 \mathrm{mM}$, in order to ensure the generation of $\mathrm{CuCl}$ precipitate, the minimum concentration of $\mathrm{Cu}^{+}$is $3 \times 10^{-5} \mathrm{M}$ according to $K_{s p}{ }^{\Phi}(\mathrm{CuCl})=c\left(\mathrm{Cu}^{+}\right) \times c\left(\mathrm{Cl}^{-}\right)$,. Moreover, the residual concentration of $\mathrm{I}^{-}$is $3.67 \times 10^{-8} \mathrm{M}$ according to $K_{s p} \Phi(\mathrm{CuI})=c\left(\mathrm{Cu}^{+}\right) \times c\left(\mathrm{I}^{-}\right)$. Then when the initial concentration is $0.4 \mathrm{mM}$, the uptake efficiency can reach about $99.0825 \%$. Therefore, $\mathrm{Cl}^{-}$cannot affect the iodide uptake of $\mathrm{Cu}$-based adsorbents.

\section{Conclusions}

Hollow spheres of metallic $\mathrm{Cu}, \mathrm{Cu} / \mathrm{Cu}_{2} \mathrm{O}$ composite and pure $\mathrm{Cu}_{2} \mathrm{O}$ were prepared by a facile solvothermal method. XRD analyses revealed that the $\mathrm{Cu}$ content of all samples can be tailored by the reaction time. TEM and SEM measurements showed that all hollow samples consisted of nanoparticles and the pores on the surface were gradually disappearing with increasing $\mathrm{Cu}$ content. $\mathrm{CuO}$ was appearing on the surface of the samples according to measurement by XPS analyses. Comparing the uptake capacity of solid and hollow $\mathrm{Cu}$-based adsorbents, as-synthesized hollow samples have higher utilization efficiencies of $\mathrm{Cu}$ content. Meanwhile, all $\mathrm{Cu}$-based adsorbents obtain the highest uptake performance when solutions are exposed to air. The uptake capacity of hollow $\mathrm{Cu}$-based adsorbents increased with increasing doping content of metallic $\mathrm{Cu}$. The maximum adsorption capacity of pure metallic $\mathrm{Cu}$ is $0.26 \mathrm{mmol} \mathrm{g}^{-1}$. Moreover, the uptake reaches optimal removal within only a few hours. Furthermore, the uptake mechanism is proposed and verified by characterization of the composites after the uptake and analysis of the experiments. Finally, the hollow $\mathrm{Cu}$-based adsorbents exhibit excellent selectivity for $\mathrm{I}^{-}$anions in the presence of large concentrations of competitive anions, such as $\mathrm{Cl}^{-}, \mathrm{SO}_{4}{ }^{2-}$ and $\mathrm{NO}_{3}{ }^{-}$, and function well in the acidic or neutral environments. Given the merits of this adsorbent, the hollow $\mathrm{Cu}$-based adsorbents may be a more effective candidate for the uptake of $\mathrm{I}^{-}$ anions from water in practical applications

Supplementary Materials: The following are available online at http:/ /www.mdpi.com/1996-1944/11/5/769/s1. Figure S1. Fitting curves of the Langmuir (a) and Freundlich models (b) for the uptake isotherms of all hollow $\mathrm{Cu}$-based adsorbents. Figure S2. Pseudo-first-order (a) and pseudo-second-order (b) kinetics models for iodide anions removal on all as-synthesized samples. Figure S3. Photographs showing the solution color changes during the uptake process of all Cu-based adsorbents. (a) o h, (b) $1 \mathrm{~h}$. (c) $1.5 \mathrm{~h}$, (d) $4.5 \mathrm{~h}$, (e) $6 \mathrm{~h}$ and (f) $12 \mathrm{~h}$. Figure S4. XRD patterns of S5, S40 and S60 after the uptake of $\mathrm{I}^{-}$anions in the presence of high concentrations 
of $\mathrm{Cl}^{-}$(a), $\mathrm{NO}_{3}^{-}$(b), $\mathrm{SO}_{4}{ }^{2-}$ (c), and $\mathrm{CO}_{3}{ }^{2-}$ (d) anions. Table S1. Isotherm parameters for the uptake of $\mathrm{I}^{-}$ anions by all hollow $\mathrm{Cu}$-based adsorbents. Table S2. Kinetic parameters for the uptake of $\mathrm{I}^{-}$anions by all hollow $\mathrm{Cu}$-based adsorbents.

Author Contributions: P.M. conceived and designed the experiments and wrote the paper; J.J., Y.P. and C.D. analyzed the data; S.Z. and Y.C. were responsible for the synthesis and the uptake test; S.C. performed X-ray diffraction studies and analyzed results; Y.Y. carried out microscopy studies and analyzed results.

Funding: This research was funded by the National Natural Science Foundation of China (grant number 51574130, 21606098 \& 21701082,), the Industry-Academia-Research Joint Innovation Fund of Jiangsu Province (grant number BY2016004-02), the Jiangsu Engineering Technology Research Center of Environmental Cleaning Materials (grant number KFK1504), the Priority Academic Program Development of Jiangsu Higher Education Institutions (PAPD), Qing Lan Project of Jiangsu Province and State Key Laboratory of Materials-Oriented Chemical Engineering (grant number KL14-14).

Conflicts of Interest: The authors declare no conflict of interest.

\section{References}

1. Rohde, R.A.; Muller, R.A. Air Pollution in China: Mapping of Concentrations and Sources. PLoS ONE 2015, 10, e0135749. [CrossRef] [PubMed]

2. Kan, H.; Chen, B.; Hong, C. Health impact of outdoor air pollution in China: Current knowledge and future research needs. Environ. Health Perspect. 2009, 117, A187. [CrossRef] [PubMed]

3. Jia, Y.; Gao, Y.; Xu, Z.; Wong, K.P.; Lai, L.L.; Xue, Y.; Dong, Z.Y.; Hill, D.J. Powering China's sustainable development with renewable energies: Current status and future trend. Electr. Power Compon. Syst. 2015, 43, 1193-1204. [CrossRef]

4. Guo, X.; Guo, X. Nuclear power development in China after the restart of new nuclear construction and approval: A system dynamics analysis. Renew. Sustain. Energy Rev. 2016, 57, 999-1007. [CrossRef]

5. Theiss, F.L.; Ayoko, G.A.; Frost, R.L. Iodide removal using LDH technology. Chem. Eng. J. 2016, 296, 300-309. [CrossRef]

6. Inoue, $\mathrm{H}$. Transport of ${ }^{125} \mathrm{I}$ and ${ }^{36} \mathrm{Cl}$ across an anion-exchange paper membrane. Appl. Radiat. Isot. 2002, 56, 659-665. [CrossRef]

7. Inoue, $\mathrm{H}$. Radioactive iodine and chloride transport across a paper membrane bearing trimethylhydroxy propylammonium anion exchange groups. J. Membr. Sci. 2003, 222, 53-57. [CrossRef]

8. Inoue, $\mathrm{H}$. Effects of co-ions on transport of iodide ions through a non-conventional anion exchange paper membrane. J. Membr. Sci. 2004, 228, 209-215. [CrossRef]

9. Liu, S.; Kang, S.; Wang, H.; Wang, G.; Zhao, H.; Cai, W. Nanosheets-built flowerlike micro/nanostructured $\mathrm{Bi}_{2} \mathrm{O}_{2.33}$ and its highly efficient iodine removal performances. Chem. Eng. J. 2016, 289, 219-230. [CrossRef]

10. Liu, L.; Liu, W.; Zhao, X.; Chen, D.; Cai, R.; Yang, W.; Komarneni, S.; Yang, D. Selective capture of iodide from solutions by microrosette-like $\delta-\mathrm{Bi}_{2} \mathrm{O}_{3}$. ACS Appl. Mater. Interfaces 2014, 6, 16082-16090. [CrossRef] [PubMed]

11. Mao, P.; Qi, B.; Liu, Y.; Zhao, L.; Jiao, Y.; Zhang, Y.; Jiang, Z.; Li, Q.; Wang, J.; Chen, S. AgII doped MIL-101 and its adsorption of iodine with high speed in solution. J. Solid State Chem. 2016, 237, 274-283. [CrossRef]

12. Liu, S.; Wang, N.; Zhang, Y.; Li, Y.; Han, Z.; Na, P. Efficient removal of radioactive iodide ions from water by three-dimensional $\mathrm{Ag}_{2} \mathrm{O}-\mathrm{Ag} / \mathrm{TiO}_{2}$ composites under visible light irradiation. J. Hazard. Mater. 2015, 284, 171-181. [CrossRef] [PubMed]

13. Lefèvre, G.; Walcarius, A.; Ehrhardt, J.J.; Bessière, J. Sorption of iodide on cuprite $\left(\mathrm{Cu}_{2} \mathrm{O}\right)$. Langmuir 2000, 16, 4519-4527. [CrossRef]

14. Mao, P.; Liu, Y.; Jiao, Y.; Chen, S.; Yang, Y. Enhanced uptake of iodide on $\mathrm{Ag} @ \mathrm{Cu}_{2} \mathrm{O}$ nanoparticles. Chemosphere 2016, 164, 396-403. [CrossRef] [PubMed]

15. Mao, P.; Qi, L.; Liu, X.; Liu, Y.; Jiao, Y.; Chen, S.; Yang, Y. Synthesis of $\mathrm{Cu} / \mathrm{Cu}_{2} \mathrm{O}$ hydrides for enhanced removal of iodide from water. J. Hazard. Mater. 2017, 328, 21-28. [CrossRef] [PubMed]

16. Mao, P.; Liu, Y.; Liu, X.; Wang, Y.; Liang, J.; Zhou, Q.; Dai, Y.; Jiao, Y.; Chen, S.; Yang, Y. Bimetallic AgCu/Cu $2 \mathrm{O}$ hybrid for the synergetic adsorption of iodide from solution. Chemosphere 2017, 180, 317-325. [CrossRef] [PubMed]

17. Hu, J.; Chen, M.; Fang, X.; Wu, L. Fabrication and application of inorganic hollow spheres. Chem. Soc. Rev. 2011, 40, 5472-5491. [CrossRef] [PubMed] 
18. $\mathrm{Xu}, \mathrm{H}$.; Wang, W. Template Synthesis of Multishelled $\mathrm{Cu}_{2} \mathrm{O}$ Hollow Spheres with a Single-Crystalline Shell Wall. Angew. Chem. Int. Ed. 2007, 46, 1489-1492. [CrossRef] [PubMed]

19. Yang, S.; Zhang, S.; Wang, H.; Yu, H.; Fang, Y.; Peng, F. Facile synthesis of self-assembled mesoporous CuO nanospheres and hollow $\mathrm{Cu}_{2} \mathrm{O}$ microspheres with excellent adsorption performance. RSC Adv. 2014, 4, 43024-43028. [CrossRef]

20. Gao, J.; Li, Q.; Zhao, H.; Li, L.; Liu, C.; Gong, Q.; Qi, L. One-Pot Synthesis of Uniform $\mathrm{Cu}_{2} \mathrm{O}$ and CuS Hollow Spheres and Their Optical Limiting Properties. Chem. Mater. 2008, 20, 6263-6269. [CrossRef]

21. Hung, L.-I.; Tsung, C.-K.; Huang, W.; Yang, P. Room-Temperature Formation of Hollow $\mathrm{Cu}_{2} \mathrm{O}$ Nanoparticles. Adv. Mater. 2010, 22, 1910-1914. [CrossRef] [PubMed]

22. Oscarson, D.W.; Miller, H.G.; Watson, R.L. The potential effectiveness of mercury minerals in decreasing the level of iodine-129 in a nuclear fuel waste disposal vault. Nucl. Chem. Waste Manag. 1986, 6, 151-157. [CrossRef]

23. Yao, W.; Li, F.-L.; Li, H.-X.; Lang, J.-P. Fabrication of hollow $\mathrm{Cu}_{2} \mathrm{O} @ \mathrm{CuO}$-supported Au-Pd alloy nanoparticles with high catalytic activity through the galvanic replacement reaction. J. Mater. Chem. A 2015, 3, 4578-4585. [CrossRef]

24. Yan, F.; Ma, R.; Ma, X.; Cui, K.; Wu, K.; Chen, M.; Li, Y. Ethanolysis of Kraft lignin to platform chemicals on a MoC1-x/Cu-MgAlOz catalyst. Appl. Catal. B 2017, 202, 305-313. [CrossRef]

25. Mohamed, R.M.; Aazam, E.S. Preparation and characterization of core-shell polyaniline/mesoporous $\mathrm{Cu}_{2} \mathrm{O}$ nanocomposites for the photocatalytic oxidation of thiophene. Appl. Catal. A 2014, 480, 100-107. [CrossRef]

26. Mamba, G.; Pulgarin, C.; Kiwi, J.; Bensimon, M.; Rtimi, S. Synchronic coupling of $\mathrm{Cu}_{2} \mathrm{O}(\mathrm{p}) / \mathrm{CuO}(\mathrm{n})$ semiconductors leading to Norfloxacin degradation under visible light: Kinetics, mechanism and film surface properties. J. Catal. 2017, 353, 133-140. [CrossRef]

27. Haq, Z.; Bancroft, G.M.; Fyfe, W.S.; Bird, G.; Lopata, V.J. Sorption of iodide on copper. Environ. Sci. Technol. 1980, 14, 1106-1110. [CrossRef]

28. Lefèvre, G.; Bessière, J.; Ehrhardt, J.-J.; Walcarius, A. Immobilization of iodide on copper(I) sulfide minerals. J. Environ. Radioact. 2003, 70, 73-83. [CrossRef]

29. Liu, Y.; Gu, P.; Jia, L.; Zhang, G. An investigation into the use of cuprous chloride for the removal of radioactive iodide from aqueous solutions. J. Hazard. Mater. 2016, 302, 82-89. [CrossRef] [PubMed]

30. Manzoor, Q.; Nadeem, R.; Iqbal, M.; Saeed, R.; Ansari, T.M. Organic acids pretreatment effect on Rosa bourbonia phyto-biomass for removal of $\mathrm{Pb}(\mathrm{II})$ and $\mathrm{Cu}(\mathrm{II})$ from aqueous media. Bioresour. Technol. 2013, 132, 446-452. [CrossRef] [PubMed]

31. Ullah, I.; Nadeem, R.; Iqbal, M.; Manzoor, Q. Biosorption of chromium onto native and immobilized sugarcane bagasse waste biomass. Ecol. Eng. 2013, 60, 99-107. [CrossRef]

32. Iqbal, M.; Khera, R.A. Adsorption of copper and lead in single and binary metal system onto Fumaria indica biomass. Chem. Int. 2015, 1, 157b-163b.

33. Ho, Y.S.; McKay, G. Pseudo-second order model for sorption processes. Process Biochem. 1999, 34, 451-465. [CrossRef]

34. Gao, S.; Yang, J.; Li, Z.; Jia, X.; Chen, Y. Bioinspired synthesis of hierarchically micro/nano-structured CuI tetrahedron and its potential application as adsorbent for $\mathrm{Cd}(\mathrm{II})$ with high removal capacity. J. Hazard. Mater. 2012, 211, 55-61. [CrossRef] [PubMed]

35. Sankapal, B.R.; Ennaoui, A.; Guminskaya, T.; Dittrich, T.; Bohne, W.; Röhrich, J.; Strub, E.; Lux-Steiner, M.C. Characterization of $\mathrm{p}$-CuI prepared by the SILAR technique on $\mathrm{Cu}$-tape/n-CuInS $\mathrm{n}_{2}$ for solar cells. Thin Solid Films 2005, 480-481, 142-146. [CrossRef]

36. Park, J.C.; Kim, J.; Kwon, H.; Song, H. Gram-Scale Synthesis of $\mathrm{Cu}_{2} \mathrm{O}$ Nanocubes and Subsequent Oxidation to $\mathrm{CuO}$ Hollow Nanostructures for Lithium-Ion Battery Anode Materials. Adv. Mater. 2009, 21, 803-807. [CrossRef]

(C) 2018 by the authors. Licensee MDPI, Basel, Switzerland. This article is an open access article distributed under the terms and conditions of the Creative Commons Attribution (CC BY) license (http:/ / creativecommons.org/licenses/by/4.0/). 